\title{
Evaluation of the quality of mammographic breast positioning: a quality improvement study
}

\author{
Julie Rouette MSc, Noémie Elfassy MD, Nathaniel Bouganim MD, Hui Yin MSc, Nathaniel Lasry PhD, \\ Laurent Azoulay PhD
}

Abstract

Background: Although there are concerns that inadequate breast positioning in mammographic examinations may lead to cancers being missed, few studies have examined the quality of breast positioning, especially in the Canadian context. Our objective was to assess the quality of breast positioning in mammographic examinations in a Quebec-wide representative sample of technologists.

Methods: This quality improvement study was part of a professional inspection launched by the Ordre des technologues en imagerie médicale, en radio-oncologie et en électrophysiologie médicale du Québec among its members. The inspection was conducted between May and July 2017 on a proportionate stratified random sample of all active technologists certified in mammography in Quebec. Each technologist provided images from 15 consecutive mammographic examinations they performed in the previous 6 months. The quality of positioning was then evaluated by senior technologists using a quality assessment tool specifically developed for this inspection. A technologist was deemed to have failed the professional inspection when at least 7 of the 15 mammographic examinations were scored as critical failures. Proportions were calculated accounting for sampling weights and correction for finite population.

Results: Among the 520 technologists certified in mammography in Quebec, 76 technologists (14.6\%) were randomly selected for the professional inspection and contributed images from 1127 mammographic examinations. Thirty-eight technologists (weighted percentage $50.3 \%, 95 \%$ confidence interval [Cl] $37.6 \%$ to $63.0 \%)$ failed the professional inspection. Overall, 492 mammographic examinations $(43.7 \%, 95 \% \mathrm{Cl} 38.6 \%$ to $48.8 \%)$ had at least 1 image scored as a critical failure.

Interpretation: Half of the technologists performing mammographic examinations in Quebec who participated in this study failed the inspection, and a substantial proportion of their mammographic examinations demonstrated critical failures in breast positioning. Overall, our findings are concordant with those of previous studies and highlight the need for additional investigations assessing the quality of breast positioning in mammographic examinations in other jurisdictions.

\footnotetext{
T $\mathrm{n}$ Canada, breast cancer is the most commonly diagnosed cancer among women and is expected to affect - 1 in 8 Canadian women in their lifetime. ${ }^{1}$ Early detection is paramount to maximizing treatment success and improving patient outcomes. Although mammography is currently the most reliable and accepted method for detecting breast cancer, it can fail to detect between $16 \%$ and $30 \%$ of breast cancers. ${ }^{2}$ Factors such as younger age and higher breast density have been shown to decrease the screening accuracy of mammography. ${ }^{2,3}$ Improper breast positioning can also decrease the diagnostic sensitivity of mammography, potentially leading to unnecessary repeat examinations, higher radiation exposure, unnecessary invasive procedures such as biopsies and surgery, and missed breast cancer cases. ${ }^{4-7}$

In recent years, there have been increasing concerns regarding the quality of breast positioning in mammographic examinations. ${ }^{4,8-10}$ In Canada, a study evaluated the quality of
}

197 mammographic examinations performed between 2004 and 2005 as part of the Quebec Breast Cancer Screening Program. ${ }^{8}$ Findings showed that $49.7 \%$ of the mammographic

Competing interests: Julie Rouette has received consulting fees from Biogen for work unrelated to this study. Nathaniel Bouganim has received consulting fees from Amgen, Novartis and Roche for work unrelated to this study. Nathaniel Lasry is a shareholder of iMD Research, which received a contract to assist with the design of the professional inspection of technologists from the Ordre des technologues en imagerie médicale, en radio-oncologie et en électrophysiologie médicale du Québec. Laurent Azoulay has received consulting fees from Janssen and Pfizer for work unrelated to this study. No other competing interests were declared.

This article has been peer reviewed.

Correspondence to: Laurent Azoulay, laurent.azoulay@mcgill.ca CMAJ Open 2021. DOI:10.9778/cmajo.20200211 
examinations did not satisfy the quality criteria for breast positioning used by the Canadian Association of Radiologists. The paucity of more recent evidence highlights the need for an updated evaluation of the quality of breast positioning and the development of a comprehensive and reliable tool that can be effectively used to assess mammographic examinations.

The Ordre des technologues en imagerie médicale, en radio-oncologie et en électrophysiologie médicale du Québec (OTIMROEPMQ) launched a professional inspection among its members to evaluate the quality of breast positioning. The objective of this study was to assess the quality of breast positioning in mammographic examinations among a representative sample of active technologists certified in mammography in the province of Quebec.

\section{Methods}

\section{Study design and setting}

We conducted a quality improvement study at the request of OTIMROEPMQ between May and July 2017. We selected a random sample of all certified medical radiation technologists with accredited training in breast imaging in Quebec who were active in 2017. Technologists were selected from the OTIMROEPMQ database, which contains up-to-date membership and accreditation information for all members.

\section{Study population}

Proportionate stratified random sampling was used to select technologists on the basis of 4 criteria: the geographic location (urban v. rural) of the centre at which the technologist worked, the annual volume of mammographic examinations performed at the centre (low v. high volume, with 2266 used as the median cut-off), the annual number of mammographic examinations performed by the technologist (low v. high, with 709 used as the median cut-off) and the technologist's years of experience $(<3 \mathrm{yr}, 3-14 \mathrm{yr}, \geq 15 \mathrm{yr}$ ) with or without continuing education. These 4 criteria generated 48 possible strata.

We then calculated sampling weights to determine how many technologists we needed to sample from each stratum to ensure that the distribution of technologists in each stratum in our study sample matched the distribution of eligible OTIMROEPMQ technologists in each stratum. Thus, 1 or more technologists were selected at random from each stratum that included at least 1 technologist. Within a given stratum, each technologist had the same probability of being selected. With 520 active technologists certified in mammography in Quebec in 2017, it was deemed that a 15\% sample $(n=78)$ would maximize feasibility while generating acceptable variances in estimates.

\section{Development of the quality assessment tool}

We developed a quality assessment tool for mammographic breast positioning to limit subjectivity while maximizing interrater agreement. We extracted quality assessment criteria used by the American College of Radiology ${ }^{11,12}$ and the Canadian Association of Radiologists, ${ }^{8}$ the United Kingdom's National Health Service Breast Screening Programme ${ }^{13}$ and the
European Guidelines for Quality Assurance in Breast Cancer Screening and Diagnosis. ${ }^{14}$

We then selected 3 senior technologists currently providing formal training in mammographic imaging and recommended by OTIMROEPMQ for their superior breast imaging expertise, to form an expert panel. They each had expertise in evaluating breast imaging data and were thus adequately skilled to recognize critical failures related to breast positioning. The selection of panel members was informed by previous findings that technologists providing formal training conduct higher quality mammographic examinations. ${ }^{9}$

Each member of the expert panel independently provided a set of criteria for evaluating the quality of breast positioning on the basis of their professional experience and training. Separate criteria were developed for craniocaudal (CC) views and mediolateral oblique (MLO) views.

For the overall quality score, we used a binary response (adequate v. critical failure) on the basis of the PGMI (perfect, good, moderate, inadequate) evaluation system used for quality assurance in mammography in the UK and elsewhere. ${ }^{13,15}$ To reduce subjectivity, we predefined the criteria by which an image would be assessed to be a critical failure. Details of the pilot evaluation and predefined criteria are provided in Appendix 1, Supplementary Methods 1, available at www. cmajopen.ca/content/9/2/E607/suppl/DC1.

The tool was tested for interrater agreement by the expert panel using 2 samples, for a final raw agreement of $97 \%$ and a Cohen $\kappa$ coefficient of 0.63 , indicating good interrater agreement (Appendix 1, Supplementary Methods 2). The final tool contained 8 criteria to evaluate positioning on $\mathrm{CC}$ view (Appendix 1, Supplementary Table 1) and 9 criteria to evaluate positioning on MLO view (Appendix 1, Supplementary Table 2).

\section{Data collection}

As part of the professional inspection, the selected technologists were asked by the OTIMROEPMQ to submit the images from 15 consecutive mammographic examinations conducted over a maximum period of 6 months in 2017. Tomosynthesis mammograms, mammograms of patients with double mastectomy or implants and mammograms of male patients were excluded.

For each mammographic examination, the technologist completed a case report form, designed and distributed by OTIMROEPMQ, abstracting selected patient characteristics from medical records (age, weight, height) and mammogram files (breast size, type of mammography, modality, specific conditions, presence of cutaneous markers, and comparison of the images with those from previous examinations). Cutaneous markers are placed on a patient's skin before mammography to help identify surgical scars, raised moles or skin lesions, for example. The American College of Radiology recommends using and documenting this practice to detect important clinical findings better. ${ }^{16} \mathrm{We}$ also collected information on whether the submitted images had been compared with those from a previous examination. It has been shown that comparisons with the images from previous mammographic 
examinations can reduce false-positive findings and recall rates. ${ }^{17}$ These variables were collected to help describe technologists' behaviours during mammography.

Characteristics of the technologists (type of training received, annual number of mammographic examinations performed, number of years of experience) and characteristics of the centres (location, number of patients, centre designation, annual number of mammographic examinations performed) were obtained from the OTIMROEPMQ.

For technologists, a passing grade was defined as a score of $60 \%$ (a minimum of 9 of 15 mammographic examinations determined to be acceptable and a maximum of 6 of 15 mammographic examinations determined to be critical failures). Consequently, if 7 or more of the 15 mammographic examinations submitted for inspection by a given technologist were judged to be critical failures, the technologist was deemed to have failed the inspection.

\section{Statistical analysis}

Given the proportionate stratified random sampling strategy we used, we calculated proportions accounting for sampling weight and correction for finite population. The modified Clopper-Pearson method was used to generate confidence intervals (CIs). As up to 15 patients had their examinations conducted by the same technologist, the variance of the estimates was estimated using the Taylor series method to account for intracluster correlation. ${ }^{18}$ Analyses were conducted using SAS software version 9.4 (SAS Institute Inc.).

\section{Ethics approval}

Ethics approval was waived by the Research Ethics Board of the Jewish General Hospital as this was a professional inspection requested by OTIMROEPMQ and deemed a quality improvement study.

\section{Results}

Of the 520 active technologists in Quebec, 78 were initially selected as part of the proportionate random stratified sampling. Of those, 1 technologist was no longer certified in mammography, while another was on maternity leave. As these technologists were alone in their respective strata, it was not possible to select additional technologists to replace them, and thus the analyses were based on data for 76 (14.6\%) technologists. The selected technologists came from 27 of the 48 possible strata and were representative of the population of technologists in Quebec (Appendix 1, Supplementary Table 3).

Table 1 presents the characteristics of the selected technologists. The majority of them worked in an urban location $(n=68,89.5 \%)$ and at a high-volume centre $(n=51,67.1 \%)$. Approximately half of them had between 3 and 14 years of mammography imaging experience $(n=42,55.3 \%)$ and about one-fifth $(n=16,21.1 \%)$ had additional qualifications in mammographic imaging.

As this was a mandatory inspection, $100 \%$ of the 76 selected technologists provided images, resulting in the submission of images from a total of 1140 mammographic examinations.

\begin{tabular}{|c|c|}
\hline Characteristic & $\begin{array}{l}\text { No. (\%) of technologists } \\
\qquad n=76\end{array}$ \\
\hline \multicolumn{2}{|l|}{ Practice location } \\
\hline Urban & $68(89.5)$ \\
\hline High-volume centre* & $51(67.1)$ \\
\hline $\begin{array}{l}\text { Performed a high annual volume of } \\
\text { examinationst }\end{array}$ & $39(51.3)$ \\
\hline \multicolumn{2}{|l|}{ Years of experience } \\
\hline$<3$ & $4(5.3)$ \\
\hline $3-14$ & $42(55.3)$ \\
\hline$\geq 15$ & $30(39.5)$ \\
\hline Received continuing education & $16(21.1)$ \\
\hline
\end{tabular}

Of these examinations, 13 had missing views or did not meet the inclusion criteria, resulting in a sample of 1127 examinations for evaluation. The characteristics of the 1127 patients who underwent these examinations and the associated mammograms are presented in Table 2. The mean age of patients was 58.7 (standard deviation [SD] 9.2) years, and the mean body mass index was 25.4 (SD 6.8). A total of 880 mammographic examinations $(78.1 \%)$ were screening examinations and $244(21.7 \%)$ were diagnostic examinations.

\section{Quality of positioning on craniocaudal view}

Overall, $15.7 \%$ (95\% CI 7.8 to 26.9) of the technologists failed to achieve the minimum passing grade of $60 \%$, as at least 7 of their $15 \mathrm{CC}$ images were scored as critical failures (Appendix 1, Supplementary Figure 1A). Table 3 presents the results of the evaluation of positioning on $\mathrm{CC}$ view for the 1127 examinations, consisting of 1127 right CC images and 1127 left CC images. The percentage of images scored as critical failures was $22.3 \%$ (95\% CI $19.0 \%$ to $25.8 \%$ ) for the right CC images and $19.0 \%$ (95\% CI $15.8 \%$ to $22.5 \%$ ) for the left CC images. For $27.6 \%$ (95\% CI $24.0 \%$ to $31.4 \%$ ) of the examinations, either the right or the left CC image was evaluated as a critical failure because of improper positioning on $\mathrm{CC}$ view.

The most common reasons for failure on CC view were poor visualization of posterior tissues $(20.2 \%$, $95 \%$ CI $16.9 \%$ to $23.9 \%)$, portion of breast cut off $(17.5 \%, 95 \%$ CI $13.9 \%$ to $21.6 \%$ ) and posterior nipple line on CC not within $1 \mathrm{~cm}$ of posterior nipple line on MLO view $(14.9 \%$, $95 \%$ CI $12.1 \%$ to 18.1\%) (Appendix 1, Supplementary Table 4).

\section{Quality of positioning on mediolateral oblique view}

A total of $19.4 \%$ (95\% CI $11.0 \%$ to $30.6 \%$ ) of the technologists failed to achieve the minimum passing grade of $60 \%$, as at least 7 of their 15 MLO images were scored as critical failures (Appendix 1, Supplementary Figure 1B). Table 3 presents the 


\begin{tabular}{|c|c|}
\hline \multicolumn{2}{|c|}{$\begin{array}{l}\text { Table 2: Baseline characteristics of patients whose } \\
\text { mammographic examinations were included in the study }\end{array}$} \\
\hline Characteristic & $\begin{array}{l}\text { No. }(\%) \text { of } \\
\text { patients* } \\
n=1127\end{array}$ \\
\hline Age, yr, mean \pm SD $†$ & $58.7 \pm 9.2$ \\
\hline Body mass index, mean \pm SD $\ddagger$ & $25.4 \pm 6.8$ \\
\hline \multicolumn{2}{|l|}{ Modality§ } \\
\hline Computed radiography & 445 (39.5) \\
\hline Digital radiography & $680(60.3)$ \\
\hline Unknown & $2(0.2)$ \\
\hline \multicolumn{2}{|l|}{ Type of examination } \\
\hline Screening & $880(78.1)$ \\
\hline Diagnostic & $244(21.7)$ \\
\hline Unknown & $3(0.3)$ \\
\hline \multicolumn{2}{|l|}{ Breast size $(\mathrm{cm})$} \\
\hline Small $(<8)$ & 465 (41.3) \\
\hline Medium (8-14.9) & $588(52.2)$ \\
\hline Large $(\geq 15)$ & $67(5.9)$ \\
\hline Unknown & $7(0.6)$ \\
\hline \multicolumn{2}{|l|}{ Breast type } \\
\hline Regular & 955 (84.7) \\
\hline Cosmetic or plastic surgery & $38(3.4)$ \\
\hline Partial mastectomy & $68(6.0)$ \\
\hline Other surgical scars & $19(1.7)$ \\
\hline Combination ${ }^{* *}$ & $19(1.7)$ \\
\hline Unknown & $28(2.5)$ \\
\hline \multicolumn{2}{|l|}{ Specific condition } \\
\hline None & $1069(94.9)$ \\
\hline Limited mobility (e.g., wheelchair) & $6(0.5)$ \\
\hline Shoulder pain & $6(0.5)$ \\
\hline Sensitive or very sensitive patient & $7(0.6)$ \\
\hline Other & $2(0.2)$ \\
\hline Unknown & $37(3.3)$ \\
\hline Cutaneous markers & $156(13.8)$ \\
\hline $\begin{array}{l}\text { Images compared with those from } \\
\text { previous examination }\end{array}$ & 929 (82.4) \\
\hline \multicolumn{2}{|c|}{$\begin{array}{l}\text { Note: } S D \text { = standard deviation. } \\
\text { *Unless indicated otherwise. } \\
\text { †Data were missing for } 8 \text { patients. } \\
\text { fData were missing for } 231 \text { patients. } \\
\text { §Computed radiography was defined as use of an offline system that uses a } \\
\text { cassette-based storage phosphor plate, which is read into a detector to create a } \\
\text { digital image. Digital radiography was defined as use of an online system that } \\
\text { uses an integrated flat panel detector to read the digital image instantly. } \\
\text { ๆIncludes reduction mammoplasty and mastopexy. } \\
\text { **Includes breast type with cosmetic or plastic surgery, or with partial } \\
\text { mastectomy or with other surgical scars or any combination of these. }\end{array}$} \\
\hline
\end{tabular}

results of the evaluation of positioning on MLO view for the 1127 mammographic evaluations. The percentage of MLO images scored as critical failures was $20.0 \%$ (95\% CI $16.3 \%$ to $24.1 \%$ ) for right MLO images and $17.6 \%$ (95\% CI $14.0 \%$ to $21.6 \%$ ) for left MLO images. For $26.0 \%$ (95\% CI $21.6 \%$ to $30.8 \%$ ) of the mammographic examinations, either the right or the left image was evaluated as a critical failure because of improper positioning on MLO view.

The most common reasons for failure on MLO view were poor visualization of posterior tissues $(16.1 \%, 95 \%$ CI $12.5 \%$ to $20.2 \%$ ), portion of breast cut off $(14.3 \%, 95 \%$ CI $10.8 \%$ to $18.4 \%$ ) and inframammary angle not clearly demonstrated $(14.0 \%$, 95\% CI $10.8 \%$ to $17.8 \%$ ) (Appendix 1, Supplementary Table 4).

\section{Overall quality of positioning}

We combined the bilateral CC and MLO images to evaluate the overall quality of each mammographic examination. Thirty-eight of the 76 technologists (weighted percentage $50.3 \%, 95 \%$ CI $37.6 \%$ to $63.0 \%$ ) failed to achieve the minimum passing grade of $60 \%$, as at least 7 of their 15 mammographic examinations were scored as critical failures (Appendix 1, Supplementary Figure 2). Table 4 presents the overall quality of positioning by combining the results for both the $\mathrm{CC}$ and MLO views. An overall failure occurred when at least 1 of the 4 views was evaluated as a critical failure.

A total of 492 of the 1127 mammographic evaluations (43.7\%, $95 \%$ CI $38.6 \%$ to $48.8 \%$ ) had a critical failure in at least 1 of the 4 views. Of those 492 examinations, 201 (40.9\%, $95 \%$ CI $35.7 \%$ to $46.2 \%$ ) had a critical failure in 1 of the 4 images, $210(42.7 \%$, 95\% CI $38.2 \%$ to $47.3 \%)$ had a critical failure in 2 of the 4 images, and 81 (16.5\%, 95\% CI $13.0 \%$ to $20.4 \%$ ) had a critical failure in either 3 or all 4 images. Additionally, in 101 of the 492 examinations $(20.5 \%$, 95\% CI $16.5 \%$ to $25.1 \%$ ), there were critical failures in the CC and MLO views of the same breast, meaning that those patients had no acceptable images for 1 of their breasts.

\section{Failure rate by technologist and patient characteristics}

We examined the percentage of failures according to patient and technologist characteristics (Appendix 1, Supplementary Tables 5 and 6). Overall, $76.4 \%$ of technologists working in low-volume centres failed the evaluation compared with $43.7 \%$ of technologists working in high-volume centres (difference $-32.7 \%, 95 \%$ CI $-56.2 \%$ to $9.2 \%$ ). Technologists who did not have additional qualifications had a failure rate of $51.9 \%$ compared with $30.0 \%$ of those who had additional qualifications (difference $-21.9 \%, 95 \%$ CI $-49.3 \%$ to $5.6 \%)$. In terms of patient characteristics, the failure rate was higher among patients with higher body mass index $(\geq 30.0)$ than among patients with lower body mass index $(<30)(50.8 \%$ v. $37.0 \%$, respectively; difference $-13.9 \%, 95 \% \mathrm{CI}-21.8 \%$ to $-6.0 \%)$.

\section{Interpretation}

In a representative sample of technologists certified in mammography in Quebec, 50.3\% failed the professional inspection, defined as having at least 7 out of 15 mammographic examinations with critical failures in breast positioning. 


\begin{tabular}{|c|c|c|c|c|}
\hline \multirow[b]{2}{*}{ Assessment category } & \multicolumn{2}{|c|}{ Right-side images } & \multicolumn{2}{|c|}{ Left-side images } \\
\hline & No. & $\%(95 \% \mathrm{Cl})$ & No. & $\%(95 \% \mathrm{Cl})$ \\
\hline \multicolumn{5}{|l|}{ CC view } \\
\hline Adequate & 876 & 77.7 (74.2 to 81.0$)$ & 913 & 81.0 (77.5 to 84.2$)$ \\
\hline Critical failure & 251 & 22.3 (19.0 to 25.8 ) & 214 & 19.0 (15.8 to 22.5$)$ \\
\hline Total & 1127 & 100.0 & 1127 & 100.0 \\
\hline \multicolumn{5}{|l|}{ MLO view } \\
\hline Adequate & 902 & 80.0 (75.9 to 83.7 ) & 929 & 82.4 (78.4 to 86.0$)$ \\
\hline Critical failure & 225 & 20.0 (16.3 to 24.1$)$ & 198 & 17.6 (14.0 to 21.6$)$ \\
\hline Total & 1127 & 100.0 & 1127 & 100.0 \\
\hline
\end{tabular}

\begin{tabular}{|c|c|c|c|c|c|c|}
\hline \multirow[b]{2}{*}{ Assessment category } & \multicolumn{2}{|c|}{ Overall CC view } & \multicolumn{2}{|c|}{ Overall MLO view } & \multicolumn{2}{|c|}{$\begin{array}{l}\text { Overall mammographic } \\
\text { examination }\end{array}$} \\
\hline & No. & $\%(95 \% \mathrm{Cl})$ & No. & $\%(95 \% \mathrm{Cl})$ & No. & $\%(95 \% \mathrm{Cl})$ \\
\hline Adequate & 816 & 72.4 (68.6 to 76.0$)$ & 834 & 74.0 (69.2 to 78.4$)$ & 635 & $56.3(51.2$ to 61.4$)$ \\
\hline Critical failure & 310 & 27.6 (24.0 to 31.4 ) & 293 & 26.0 (21.6 to 30.8$)$ & 492 & 43.7 (38.6 to 48.8$)$ \\
\hline Total & 1127 & 100.0 & 1127 & 100.0 & 1127 & 100.0 \\
\hline
\end{tabular}

Furthermore, in 492 (43.7\%) of the 1127 mammographic examinations evaluated, there was a critical failure in at least 1 of the 4 views, and in 101 (20.5\%) of these examinations, there was an entire breast without an adequate image.

Overall, our findings are consistent with the results of 3 other studies that have examined the quality of mammographic examinations performed as part of the Quebec Breast Cancer Screening Program. In these studies, improper breast positioning was the most common factor affecting the quality of mammographic examinations, with failure rates of $22.6 \%$, $37.2 \%$ and $55.0 \%$, respectively. ${ }^{5,8,19}$

There is some evidence suggesting that quality monitoring of mammographic examinations and up-to-date positioning training, rather than the technologist's years of experience, lead to higher quality images. In a Dutch study, newly trained technologists were more likely to demonstrate adequate breast positioning than experienced technologists (97\% v. $86 \%$, respectively, for CC views and $92 \%$ v. $84 \%$, respectively, for MLO views). ${ }^{20}$ In a Quebec study, technologists who underwent hands-on positioning training were more likely to demonstrate adequate positioning than those who did not (adjusted proportion ratio $1.3,95 \%$ CI 1.1 to 1.5$).{ }^{9}$ In a study in a US tertiary care academic medical centre, a higher proportion of mammographic examinations met the American College of Radiology breast positioning criteria after technologists underwent positioning training consisting of lectures, hands-on training and positioning coaching, compared with their baseline mammogram audit $(80 \%$ v. $67 \%$, respectively). ${ }^{21}$ In our study, the presence or absence of continuing education led to a more pronounced between-group difference in failure rate than years of experience, although the confidence intervals overlapped.

Patient characteristics that have been associated with lower quality breast positioning should also be targeted in quality improvement initiatives. In an earlier Quebec study, there was a higher mammographic examination failure rate among patients with a body mass index greater than or equal to 30 than among those with a body mass index less than 25 (53.8\% v. $27.9 \%$, respectively), for an adjusted relative risk of 1.9 (95\% CI 1.2 to 3.1). ${ }^{8}$ These findings are also consistent with our results: we found that body mass index was associated with the highest between-group difference in failure rates among all of the patient characteristics we examined. Together, these results could provide insights into the specific challenges that should be addressed during additional training.

In our study, a substantial number of technologists failed the inspection despite having a certification in breast imaging. After we shared these findings with the Quebec Ministry of Health and Social Services, the OTIMROEPMQ temporarily stopped issuing new licences to technologists until a new education program for technologists with a specific focus on 
positioning quality was developed in collaboration with the ministry. Our study highlights the need for other jurisdictions and professional associations to assess breast positioning quality in their settings.

Our study has several strengths. Our proportionate stratified random sampling strategy resulted in a representative sample of certified technologists currently practising in Quebec. In addition, the quality assessment tool we used for the evaluation yielded good interrater agreement between the expert evaluators.

\section{Limitations}

As with all evaluations that use quality assessment tools, our study had some inherent subjectivity. In addition, because the tool was specifically developed for this professional inspection, it was not possible to compare the results directly with those generated using other assessment methods. Thus, future studies will be needed to compare this tool with other assessment methods in different settings.

\section{Conclusion}

Half of the technologists who participated in this study failed a professional inspection aimed at assessing the quality of mammographic breast positioning. Overall, these findings are concordant with previous studies and highlight the need for additional investigations in other jurisdictions.

\section{References}

1. Canadian Cancer Statistics Advisory Committee. Canadian cancer statistics 2019. Toronto: Canadian Cancer Society; 2019.

2. Fuller MS, Lee CI, Elmore JG. Breast cancer screening: an evidence-based update. Med Clin North Am 2015;99:451-68.

3. Carney PA, Miglioretti DL, Yankaskas BC, et al. Individual and combined effects of age, breast density, and hormone replacement therapy use on the accuracy of screening mammography. Ann Intern Med 2003;138:168-75.

4. Richli Meystre N, Henner A, Sà Dos Reis C, et al. Characterization of radiographers' mammography practice in five European countries: a pilot study. Insights Imaging 2019;10:31.

5. Guertin M-H, Théberge I, Zomahoun HTV, et al. Mammography clinical image quality and the false positive rate in a Canadian breast cancer screening program. Can Assoc Radiol 7 2018;69:169-75.

6. Sweeney R-JI, Lewis SJ, Hogg P, et al. A review of mammographic positioning image quality criteria for the craniocaudal projection. Br $\mathcal{F}$ Radiol 2018; 91:20170611.

7. Mercieca N, Portelli JL, Jadva-Patel H. Mammographic image reject rate analysis and cause: a national Maltese study. Radiography (Lond) 2017;23: $25-31$.

8. Guertin M-H, Théberge I, Dufresne M-P, et al. Clinical image quality in daily practice of breast cancer mammography screening. Can Assoc Radiol 7 2014;65:199-206.

9. Guertin M-H, Théberge I, Zomahoun HTV, et al. Technologists' characteristics and quality of positioning in daily practice in a Canadian breast cancer screening program. Acad Radiol 2016;23:1359-66.

10. Popli MB, Teotia R, Narang M, et al. Breast positioning during mammography: mistakes to be avoided. Breast Cancer (Auckl) 2014;8:119-24.

11. Mammography accreditation clinical image review sheet. Reston (VA): American College of Radiology (ACR) Accreditation. Available: https:// www.acraccreditation.org/-/media/ACRAccreditation/Documents/Mammography/ Clinical-Image-Review-Sheet---MAP.pdf (accessed 2020 Nov. 3).

12. Mammography quality control manual. Reston (VA): American College of Radiology; 1999.
13. National Quality Assurance Coordinating Group for Radiography; National Breast Screening Programme (Great Britain); NHS Cancer Screening Programmes. Quality assurance guidelines for mammograpby including radiographic quality control. NHSBSP publication no 63. Sheffield (UK): NHS Cancer Screening Programmes; 2006.

14. European guidelines for quality assurance in breast assurance in breast cancer screening and diagnosis. 4th ed. Perry N, Broeders M, de Wolf C, et al, editors. Luxembourg: Office for Official Publications of the European Communities; 2006.

15. National accreditation standards. Breastscreen Australia; 2019. Available: https://www.cancerscreening.gov.au/internet/screening/publishing.nsf/ Content/CA8C934AA0B7BA64CA257EFA001C67D7/\$File/BSA\%20NAS\%20 Commentary\%20January\%202019\%20FINAL.pdf (accessed 2020 Nov. 3).

16. ACR practice parameter for the performance of screening and diagnostic mammography. Reston (VA): American College of Radiology; 2018.

17. Hayward JH, Ray KM, Wisner DJ, et al. Improving screening mammography outcomes through comparison with multiple prior mammograms. AfR $\mathrm{Am}$ F Roentgenol 2016;207:918-24.

18. Wolter K. Introduction to variance estimation. New York: Springer-Verlag; 1985.

19. Théberge I, Guertin M-H, Vandal N, et al. Clinical image quality and sensitivity in an organized mammography screening program. Can Assoc Radiol 7 2018;69:16-23.

20. van Landsveld-Verhoeven C, den Heeten GJ, Timmers JM, et al. Mammographic positioning quality of newly trained versus experienced radiographers in the Dutch breast cancer screening programme. Eur Radiol 2015;25:3322-7.

21. Pal S, Ikeda DM, Jesinger RA, et al. Improving performance of mammographic breast positioning in an academic radiology practice. AfR Am $\mathcal{J}$ Roentgenol 2018;210:807-15.

Affiliations: Department of Epidemiology, Biostatistics and Occupational Health (Rouette, Azoulay), McGill University; Centre for Clinical Epidemiology (Rouette, Yin, Azoulay), Lady Davis Institute for Medical Research, Jewish General Hospital, Montréal, Que.; Department of Medicine (Elfassy), University of Toronto, Toronto, Ont.; Gerald Bronfman Department of Oncology (Bouganim, Azoulay), McGill University; iMD Research (Lasry), Montréal, Que.

Contributors: Nathaniel Lasry and Laurent Azoulay designed the study. Julie Rouette, Hui Yin and Laurent Azoulay did the analyses. All authors interpreted the data. Julie Rouette wrote the manuscript, which all authors critically revised for important intellectual content. All authors provided final approval of the manuscript and agreed to be accountable for all aspects of the work.

Funding: This work was supported by the Ordre des technologues en imagerie médicale, en radio-oncologie et en électrophysiologie médicale du Québec (OTIMROEPMQ), which commissioned iMD Research to conduct the inspection and analyze the data. The OTIMROEPMQ provided input into all of the steps of the inspection but did not develop the protocol for the inspection or analyze the data. Julie Rouette is the recipient of a doctoral award from the Canadian Institutes of Health Research (FRN-152254) and the Fonds de recherche du Québec - Santé. Laurent Azoulay holds a chercheur-boursier senior award from the Fonds de recherche du Québec - Santé and is the recipient of a William Dawson Scholar award from McGill University.

Content licence: This is an Open Access article distributed in accordance with the terms of the Creative Commons Attribution (CC BY-NC-ND 4.0) licence, which permits use, distribution and reproduction in any medium, provided that the original publication is properly cited, the use is noncommercial (i.e., research or educational use), and no modifications or adaptations are made. See: https://creativecommons.org/licenses/by-nc-nd/4.0/

Data sharing: The data are not publicly available.

Acknowledgements: The authors thank Josée Sirois, Guylaine Ouimet and Karine Morency for their evaluation of the mammograms.

Supplemental information: For reviewer comments and the original submission of this manuscript, please see www.cmajopen.ca/content/9/2/ E607/suppl/DC1. 